\title{
Building the Road to Prosperity for Xicang Civil Culture Based on "One Belt, One Road"
}

\author{
Jing Sun, Genghua Zou, Shuodong Wang and Lili Huang \\ Art college of Xi'an university, 710065
}

Keywords: "One Belt, One Road"; Xicang; Civil culture; Prosperity and revival

\begin{abstract}
Xicang market, located in the Lianhu District of Xi'an, is a famous flower bird market in the middle of the northbound backstreet of northwest corner of the temple in Xi'an city. In a very long period of time, every Thursday and Sunday traditional opening, there will be a lot of people to visit the bird market. In history, Xicang is the national warehouse, and now it becomes a military warehouse, residential area and flower bird market, which has become a very typical gathering place of civil culture. Civil culture, accumulating various aspects of socio-economic politics in the corresponding historical stage, is the epitome of popular culture and national cultural spirit and reflects the public cultural changes, which is also in line with the mainstream of Xi'an aesthetic taste. Therefore, in the fast development of social economy, to adapt to the form of the Xicang flower bird market, meet and focus with the street culture of Xi'an, we need to understand how to tap the historical and cultural connotation of Xi'an in the positive role based on the basic situation of "One Belt, One Road". It is the focus of this paper to explore the marketing coherence strategy of Xicang market and civil culture of Xi'an, so as to exert the ancient cultural value of Xicang market and appreciate the Xicang unique cultural deposits of the new era.
\end{abstract}

\section{Introduction}

In the 90s of last century, Xicang flower bird market occupied as much as the two alleys. Huge range of operations attracted a variety of selling deeds and flower bird vendors when the market was opened. Especially in the summer, there would be some crowds to fight crickets and also some onlookers. A variety of birdcages were hung on the branches of the trees in the streets and lanes. There is a place where people have folk, there are folk local cultures. With the passage of time, every holiday or market, many small vendors will come over, gathering here a variety of small business and miscellaneous markets, which makes Xicang to be the best place to trade in Xi'an people's mind, with enormous amount of people and a wide geographical area. With the increasing prosperity of small commodity economy in the new era and the gradual improvement of people's living standards, Xicang flower bird market has become a very lively big market radiating two kilometers. There is no additional charge, thus promoting the flourishing and developing of the small commodity business.

\section{New developing situation of Xi'an under "One Belt, One Road"}

\section{The Influence of the development, construction and marketing propaganda of Xicang civil culture on Xi'an}

Civil culture makes Shaanxi and Xi'an itself as a cultural province of the important gathering city, of which its rich historical and cultural connotations can be seen by the world. Many foreign tourists and small commodity buyers come over Xi'an, the traffic and merchandise gathering place. People will be attracted by its rich historical and cultural heritage. The cultural deposit of Xicang market, from the beginning of Zhou, stretching for thousands of years, has a complete set of perfect system for the formation and operation of the civil culture. Although in the process of modern marketing propaganda, many of the development trends are somewhat inadequate, the continuous deduction and marketing situation of civil culture has a more important impact indeed for the overall construction of Xi'an. The development of civil culture, first of all caters to ordinary 
people's love of traditional culture, as well as the daily needs of the development of typical life. With the situation of development of folk culture form being richer and demand for innovative development of civil culture being relatively higher, Xi'an is dependent on the traditional folk customs, which has penetrated into the economy and people travel and other aspects of the development of industry changes. Therefore, the promotion and development of traditional culture, is bound to promote the evolution of folk culture, especially playing a very good supporting role for some retentions of the typical Shaanxi characteristics. For example, Shaanxi Eight Strange, Guanzhong paper cutting, Guanzhong clay sculpture, and Xicang flower bird market in the civil culture, these typical taste and rich relevance of the folk culture will naturally become the new business card of the traditional city, Xi'an, in the new century development in the market circulation and marketing strategy, highlighting the important role of Xi' an as the natural history of the Chinese national museum praised by the world. The glorious history of China's 13 historical dynasties makes the cultural development of Xi'an have a unique advantage. Xi'an needs the traditional folk culture and the civil culture of Xicang flower bird market, and vice versa, the civil culture also promotes the development of Xi'an tourism and business, which has effectively promoted the historical changes of the city and the protection of the neighborhood, making Xi'an a very unique historical city in China's history, and its new changes in style and classical tradition have brought different taste to Xi'an.

\section{The historical background of Xicang culture}

Currently, Xicang civil culture has attracted the national government's attention. In the strong development of developer's and the active support of national policy, Xicang civil culture has been a well-known folk culture to be retained, which concentrates flowers and birds and a variety of typical cultural significance and natural significance of the folk culture, produces in the streets and lanes, and has a typical business propensity. As a result of the small commodity market and the needs of the real daily life of the public, Xicang flower bird market becomes flourishing, and the daily needs and mentality of the public are revealed through the small commodity market. There are small businessmen where there are civil cultures. These civil cultures are to meet people's physical and psychological needs, and the appearance is very simple, with a very specific aesthetic intention. Xicang flower bird market is preserved in Xi'an streets, with a very typical means of the civil culture gathering place, which in ancient times was the country's important warehouse, and now become the location of Xi'an military warehouse. This is because every Thursday and Sunday, the region is full of people and very lively. Therefore, as itself having a very profound cultural heritage of Xi'an, Shaanxi, these colorful folk cultures, with the small vendors' shout and the flow of people in the city, have gradually formed a gathering picture of typical community life form with a very regional characteristics, lighting the history of the Chinese people. These comprehensive folk cultures and civil cultures always continuously evolve with the evolution of human civilization. Nowadays, in the background of the cultural development of "One Belt, One Road" in our country, people pay more attention to the traditional folklore, especially the history and culture, which is changed with the evolution and birth of culture. Both refined and popular tastes of the civil culture have become the foothold of the Chinese culture going to the world, the globalization of economic development, and adapting to the developing steps of "One Belt, One Road". With the development of social development and the renewal of the times, the folk culture of flower bird market has been given a new era and economic significance due to the change and alternation of history and reality.

\section{The implication and connotation of civil culture}

The connotation of the world culture itself is linked with the development of the market. For example, in the Xicang market, due to the connection of several small commodity vendors, the civil culture in Xi'an contains the communications between people, especially in the flower bird market, in those years, people liked to play birds and grasshoppers, therefore, Xi'an civil culture in the noisy and flow was called the flowing cultural types. And even some people exaggerated that if you do 
not know Xicang, you are not real Xi' an people. Now, whether natives or visitors to Xi'an are very like the interesting symbol of civilization, coming to the streets of small town in the city and feeling the mystery of history and the inheritance of cultural heritage. The inside information of civil culture commonly cannot be replaced by the traditional official culture. It has very good feelings to come to the ancient city of Xi'an, come to small side of the amazing ancient city wall and see the subtleties of flower bird market for understanding the local folklore, tasting the local snacks, appreciating old city and feeling the national customs and cultures with unique charm.

\section{Opportunities and challenges faced by Xicang civil culture in the new era}

Development situation of Xicang civil culture in Xi'an. The form of folk culture is single.The civil culture is naturally formed in the continuous evolution of city residents and small vendors. Therefore, due to the lack of unified planning, it is definitely slightly inadequate to cater the policy of "One Belt, One Road" in the development of modern century. For example, Xicang market folk culture is relatively simple; this is because these single folk cultures don't make a lot of combination of material and cultural points. Warehouse and flower bird market are the most famous in Xicang, but this traditional way and business strategy have been unable to meet the rapid development of modern economy. As the warehouse itself, it does not have very important profit function, and as a flower bird market, because now people do not have a big demand for birds and other flowers and fish, and coupled with the impact of the electricity business network, the weakening of the economic role, and the lagging propaganda means, it makes the folk culture too single in today's development without more freshness. These typical cultural attractions do not play very good innovative role for Xi'an, which can only make changes in the form and cannot really attract people without refreshing publicity.

The folk culture lacks innovation

Because the folk culture is too single, many traditional cultures in the long process of historical evolution, although are very sophisticated, some typical folk ruins have been destructed in different degrees, and many folk cultures and intangible heritages are also facing loss. Although Xi'an is known as the king of the world's cultural and folklore, in the process of the development and evolution of Xi'an culture, people's innovation has not been well highlighted, especially for those rich folk cultures that are mismanaged in the process of communication, even faced with the dying of the embarrassing situation. The cultural development of Xi'an structure does not focus on the promotion and development of traditional culture, and does not achieve the exchange of advancing with the times, of which the traditional culture cannot introduce new, resulting in innovation lag, restricting the development of civil culture in Xi'an, and affecting the continuation of its vitality.

The traditional culture is underdeveloped

As traditional culture and economic development cannot be linked, it cannot reflect the essence of economic development strategy "One Belt, One Road", and the degree of integration of the domestic and international cultural and economic structure is very poor, so the lacks of traditional culture development potential, the traditional culture and cultural development concept result in the unable strict hooks for the development of cultural system and cultural and economic development. $\mathrm{Xi}$ 'an is always the appearance of the ancient capital presenting in front of people, but the development of Xi'an in the history and culture cannot keep pace with times with the development of modern economy, so the speed of development of Xi'an's cultural industry cannot be compared with other developed countries and cities. This has also led to the gradual weakness of Xi'an civil culture in the process of development, especially the flower bird market, which makes that many people relying their living standards on it cannot be guaranteed, many interesting folk culture gradually die, many small vendors around gradually change their careers, and folk culture disappears, presenting a sense of decline.

Opportunities for the development of Xicang culture. Modern and traditional cultures have the possibility of integration. The economic development strategy "One Belt, One Road" 
makes the Xi'an government attach great importance to the process of integration and convergence with the international economy, especially for the integration of economy and culture between developed countries and cities, hoping to make innovations based on culture, thus to develop the new bright spots of cultural development in the new era, which makes unremitting efforts on the effective promotion of Xi'an city construction and historical district style protection and the formation of new cultural tourism highlights. Therefore, the integration opportunity of Xicang culture combined with modern culture and traditional culture makes the culture have a new base to introduce new, especially in Xi'an Xicang city district cultural resources that are very valuable, fully tapped the cultural connotation may obtain very rich economy and resource returns.

\section{Its rich historical and cultural relics of Xi'an}

Xi'an is the gathering place of the world's historical and cultural heritage, and is the city of the world history museum, so its rich historical and cultural resources are the most lucrative economic resource base. The civil culture in the city streets of Xi'an is valued in the world with a huge base and rich historical origins. The civil culture of Xi'an, with Xicang as the representative, receives people's awareness and attention, making the improvement and development of folk culture with the possibility of sustainable development. Therefore, if we can, with the help of its rich historical connotation and diversified form, full protect the interesting and promising folk culture, connect with the successful experience of Xicang civil culture and other countries' civil culture, through learning from other countries, combine the traditional culture with modern culture under the help of rich historical and cultural relics, and innovate boldly on the basis of preserving the traditional features, we can combine the traditional features with the modern fashion elements, thus to arouse people's high attention and affection; in particular, under the economic developing situation of "One Belt, One Road", it is hoped that the fast development of Xicang culture of Xi'an can be in step with the world cultural development. For example, in the development of special food, the formation of gathering area of folk life experience tourist area, entertainment and leisure tourist area, exhibition tourist area, a variety of private home cuisines and restaurants, will combine the taste of old Xi'an with the modern elements such as modern art of cinematic art, entertainment, and leisure travel elements. To reflect the potential of leisure and entertainment development in Xi' an with a nostalgic but new cultural feature is able to retain the true life of $\mathrm{Xi}$ 'an, experience and accelerate the development of modern production and life, and build the development of Xi'an new city positioning from different angles, combine the localization of $\mathrm{Xi}$ 'an culture symbols with the spirit of the people and the clues of development of life, then you can create a new era of Xi'an Xicang civil culture area.

"One Belt, One Road" policy has brought development opportunities to Xicang. The policy of "One Belt, One Road" is proposed by our country, which is short for the Silk Road Economic Belt and the 21st century Maritime Silk Road. It is fully supported by the existing and multilateral cooperation mechanisms between China and other relevant countries. With the help of the existing very effective regional development cooperation platform, it is hoped to use the historical symbols of ancient Silk Road, hold high banner of peace and development, and carry out economic cooperation and economic and trade partnership with countries along the Belt and Road. That is, under the policy of "One Belt, One Road", it brings the development opportunity to Xicang, $\mathrm{Xi}$ 'an. It is because Xi'an itself is in the development line of "One Belt, One Road", and from the history, Xi' an is a very famous civilized city. Therefore, in the development process of "One Belt, One Road" promoted together by National Development and Reform Commission and Ministry of Foreign Affairs, the Xi'an government has also benefited, and attaches great importance to "One Belt, One Road" on the development of the economy in Xi'an. As the traditional Chinese folk culture is the important content in the economic and trade and cultural development and exchange process in the ancient Silk Road, the ancient China had unique advantages in the production of silk porcelain and a variety of small commodities. Therefore, to strengthen the economic and trade relations and strengthen exchanges between the East and the West in Xi'an, it is necessary to use traditional culture folk contents such as Xicang civil culture, which can be used not only to evoke 
the historical impression of ancient and modern cultural exchanges, but also to bring new contents for the new era of culture and economy communications.

\section{The basic strategy of perfecting the development of Xicang civil culture}

To learn from folk custom development situation from different places. Folk custom developments are boldly drawn lessons from different areas, and civil culture of Xi' an is combined with advanced culture at home and abroad. Although the roadway of the civil culture is relatively narrow, its visibility and reputation is still known to the old people in Xi'an. In the publicity and marketing process, it can not only let the people of Xi'an know, but also should let the outside tourists and outside residents understand the profound connotation of the culture and the gold content of local cultural symbols of Xi'an. It is necessary to improve the development of these things, learn from different localities and methods of development, and exert a variety of folk customs and economic development trend in northern Shaanxi to make it together, thus to promote the local civil culture improvement and development, promote the combination between old taste of Xi'an and the new culture of Shaanxi, build the native symbol of the civil culture of Xi'an from different cultural development positioning, and under the situation of learning from various folk custom development mode, make more people aware of the Xicang civil culture of $\mathrm{Xi}$ ' and flower bird market, and light the important content of cultural tourism highlights in the new historical period style point of view.

Bold layout based on the liberation of ideas and innovative concepts . Emancipating the mind, boldly innovating, and profitably developing civil culture under the pattern of innovation, with the help of universality and popularity of culture, makes the civil culture relatively fashionable. This is because these rapid development changes in the humanities make people familiar with the civil culture. Although sometimes the world culture has a certain degree of vulgarity, if developed in the field of creative ideas, you can make the civil culture become both refined and popular tastes, with a strong impact of the cultural level. As the cultural connotation and concept covers a very wide range, in order to make a strong atmosphere of life culture and traditional culture of the bottom of the people become enduring bright spot, you need to take the essence of the characteristics of cultural phenomena and popular culture in the urbanization process, creatively applying in a higher level of cultural expression. Civil culture has a unique value and beauty, and the layout of the civil culture needs the relevant departments of the government to make the contents and form of the civil culture relatively uniform on the basis of completing the urban planning and unifying development and construction planning, to support the development potential of the typical culture and regard the development and heritage of folk culture as the main task and do a good job for urban planning and a variety of roadway planning and repair management, making a positive contribution in strict control of community culture and closed cultural heritage.

Creating the main brand image of Xicang civil culture. The so-called main characteristics of the development of the Xicang civil culture is to build on the basis of the brand, create a forward-looking way of civil cultural development, give birth to a variety of cultural development budding business culture, combining the cultural and business model kink together, which makes the commercial tide impact on the market, but also makes the market culture support the commercial development, making business activities out of time and space limitations. It combines the modern network economy with commodity economy to create fast and convenient modern culture brand of Xicang civil culture and establish brand features. It can make the civil culture of new era show the commercial blend of the bustling scene in the development and evolution of "One Belt, One Road" policy. The new features of civil culture break the concept of space and time and level limitations, and guide the small commodity market and urban development revolution in the new era. 


\section{Conclusion}

In the eyes of modern scholars, entering the modern market economy, the small commodity economy and culture is bound to go beyond the embryonic stage of commercial development in the history, and will show new features of new period through cultural exchanges with times and line of cultural development definition, thus driving the re-prosperity of Xi'an economy in the field of civil culture.

\section{Acknowledgements:}

Xi'an Wenli University Students' Innovation and Entrepreneurship Training Program.

\section{Reference}

[1] Li P: Xicang: a hundred years of market regulation test the wisdom of the government. Ge Jie Dao Bao, 2017-04-25(003). In Chinese.

[2] Gao CX and Li MQ: The core values of ancient capital Xi'an and the revival of urban old districts - A Case study of the reconstruction planning of the North Gate to West Gate section of Shuncheng Lane in Xi'an. Architectural Knowledge, 2017, 37(01): 21-22+31. In Chinese.

[3] Wang X and Shi HL: Study on the spatial optimization of characteristic commercial blocks in Kaifeng City from the perspective of market culture regeneration. Jiangxi Building Materials, 2016, (20): 23-24. In Chinese.

[4] Li TS: Protection, renewal and regeneration of Taipei Historic District from the perspective of market culture. Xi'an University of Architecture and Technology, 2015. In Chinese.

[5] Shen Y: Inheritance of Beijing flavor folk culture to promote the Chinese aquarium industry to visit the Shili River flowers and birds fish market, thoughts on Yayuan market. Aquarium, 2014, (02): 32-37. In Chinese.

[6] Liu W: Bird and bird fish market is playing an anomaly. Consumption Daily, 2013-01-15(A02). In Chinese.

[7] Zhu WJ: The traditional Chinese district under the civil culture. Shanxi Architecture, 2010, 36(06): 37-39. In Chinese.

[8] Cui H and Li YZ: Relocation of Guanyuan flowers and birds and insects market. China Market, 2010, (Z4):48-49. In Chinese.

[9] Wang YS and Zuo Y: Thousand-Year-Old Well,Thousand-Year-Old Street: Civil Culture and Urban Pattern of Old North Street in Leping. Huazhong Architecture, 2012. In Chinese.

[10] Tian XM: The Development of the civil culture and the artistic style of books in the Late Ming Dynasty. Suzhou University, 2013. In Chinese.

[11]Cheng DX: Talking about "Popular Culture". QiuShi, 2013, (04): 25-27. In Chinese.

[12]Zhao BT: On the culture of market. Study \& Exploration, 2014, (05): 108-113. In Chinese. 